\title{
A Novel Methodology to Design Miniaturized Regular Planar Inverted-F Antennas Based on Parametric Simulations
}

\author{
Abdelhakim Elouadih ${ }^{1}$, Ahmed Oulad-Said ${ }^{2}$, Moha Mrabet Hassani ${ }^{1}$ \\ ${ }^{1}$ Department of Physics, Semlalia University of Sciences (FSSM), Marrakesh, Morocco; ${ }^{2}$ Department of Electrical and Telecommu- \\ nications Engineering, Royal Air Academy (ERA), Marrakesh, Morocco. \\ Email: elouadih@gmail.com, a_ouladsaid@hotmail.com, hassani@ucam.ac.ma
}

Received June $10^{\text {th }}, 2013$; revised July $10^{\text {th }}, 2013$; accepted July $17^{\text {th }}, 2013$

Copyright (C) 2013 Abdelhakim Elouadih et al. This is an open access article distributed under the Creative Commons Attribution License, which permits unrestricted use, distribution, and reproduction in any medium, provided the original work is properly cited.

\begin{abstract}
This paper describes a novel methodology to design PIFA (Planar Inverted-F Antenna) antennas based on parametric simulations. The parameters considered in the parametric design are ground plan dimensions, height of radiating plate, feeding point position, shorting plate width and position. The choice of the parameters that must be varied independently or simultanously is important to design optimized antenna. The author studied two scenarios in precedent works $[1,2]$. He exposes here a third scenario of varing antenna parameters to design and simulate by HFSS (High Frequency Simulator Structure) simulator a probe-fed dual band PIFA for the use in GSM 850 band (824 MHz - $894 \mathrm{MHz})$ and PCS 1900 band $(1850 \mathrm{MHz}-1990 \mathrm{MHz})$. The author compares the three scenarios and establishes a novel methodology to design optimized and miniaturized antennas mounted on mobile handsets.
\end{abstract}

Keywords: PIFA; HFSS; Design; Methodology

\section{Introduction}

With the development of mobile networks and wireless applications, the handset should be more miniature, while working in different bands and supporting different applications. A small mobile device currently supports GSM services, high speed mobile internet access and allows connection via $\mathrm{WiFi}$ and blue tooth capabilities. For this purpose, antennas are vowed to achieve miniaturization while maintening function requirements. The planar antennas are so compliant and their use in wireless local and wide networks increases.

For optimum system performance, the antennas must have high radiation efficiency, small volume, isotropic radiation characteristics, small backward radiation, simple and low-loss impedance matching to patches. The major types of configurations of low-profile antennas with enhanced bandwidth performance include Planar Inverted-F Antennas.

The PIFA consists in general of a ground plane, a top plate element, a feed wire attached between the ground plane and the top plate, and a shorting wire or strip that is connected between the ground plane and the top plate.

The antenna is fed at the base of the feed wire at the point where the wire connects to the ground plane. The PIFA is an attractive antenna for wireless systems where the space volume is quite limited. It requires simple manufacturing, since the radiator must only be printed. The addition of a shorting strip allows good impedance match to be achieved with a top plate that is typically less than $\lambda / 4$ long. The resulting PIFA is more compact than a conventional half-wavelength probe-fed patch antenna [3].

The miniaturization can affect radiation characteristics, bandwidth, gain, radiation efficiency and polarization purity. The miniaturization approaches are based on either geometric manipulation (the use of bend forms, meandered lines, PIFA shape, varying distance between feeder and short plate [4]) or material manipulation (loading with a high-dielectric material, lumped elements, conductors, capacitors, short plate [5]) or the environment characteristics (ground plane dimensions, coupling, measurement and fabrication errors [4]). In this case, the bi-band designed antenna is shorted to the ground plane by a plate, uses regular shapes and uses a high dielectric thin substrate under the radiating plate not above the ground plane). 
If all precedent works are concentrated on studying the effects of these elements (material, geometry, environment), the choice of a PIFA element was so improvised in the design. There are some recent works to to make algorithms or parametric simulations but they use some models concerning the traditional patch antennas [6] or they deliver the thoretical frequency from predefined parameters $[7,8]$. The author worked on parametric simulations by varing sequently the antenna parameters (scenario 1) [1] or simultanously of some parameters (scenario 2) [2]. In this paper, the author will expose a third scenario and he will compare the three scenarios before concluding about efficient methodology to design PIFA single or multiband.

The third scenario will be applied to design a dual band PIFA for the use in the GSM850 and PCS1900 bands.

\section{Antenna Design Following the Third Scenario}

\subsection{The Description of the Studied Antenna}

As shown in Figure 1, the designed antenna has a rectangular radiating patch length $L_{p}=31 \mathrm{~mm}$ and width $W_{p}$ $=70 \mathrm{~mm}$. The patch is placed at a height $\mathrm{h}$ from the ground plan. The ground plan has a length $L_{g}$ and a width $W_{g}$ equal to $W_{p}$. The patch is matched to the ground plan via a rectangular shorting plate. The shorting plate has a width $W_{s}$ and a length and it is placed in the (yz) plan at a distance $D$ from the edge centre. The the feeding point is situated at $p$ from the rear edge of the patch. The patch is fed by a $50 \Omega$ wire. The volume between the radiating plate and the ground plan is filled by air except a thin region $0.8 \mathrm{~mm}$ under the radiating patch who is composed of FR4_epoxy $\left(\varepsilon_{r}=4.4\right)$.

\subsection{The Choice of the Patch Dimensions}

It is very important for simulation by HFSS to estimate the resonant frequency that help the simulator to make a refinement mesh in a band around the resonant frequency and then give more precise values. The resonant frequency of a PIFA is approximated by the Equation (1) [9] where $F_{r}$ is the resonant frequency, $C$ is the light velocity.

$$
F_{r}=\frac{C}{4\left(L_{p}+W_{p}-W_{s}\right)} .
$$

If there is another substrate different from Air, $C$ will be $C_{0} / \sqrt{\varepsilon_{r}}$ where $C_{0}=3 \times 10^{8} \mathrm{~m} / \mathrm{s}$. For our case, the space between the patch and the ground plan is essentially air minus a $0.8 \mathrm{~mm}$ FR4 epoxy layer.

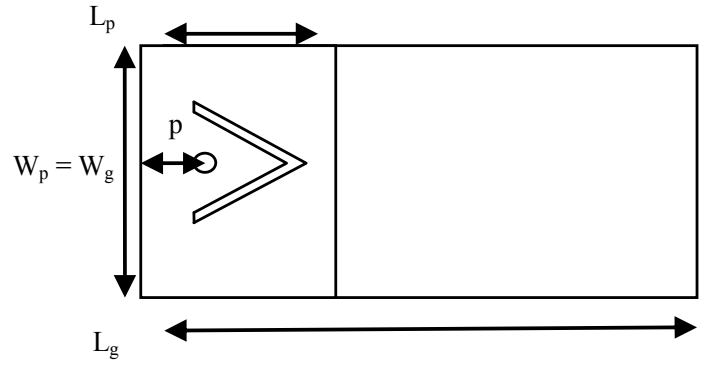

(a)

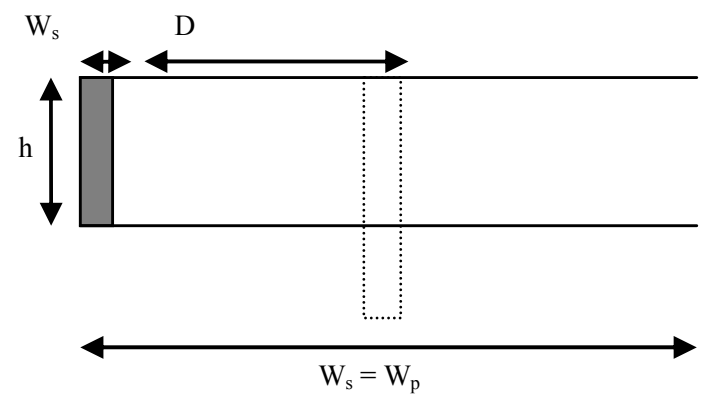

(b)

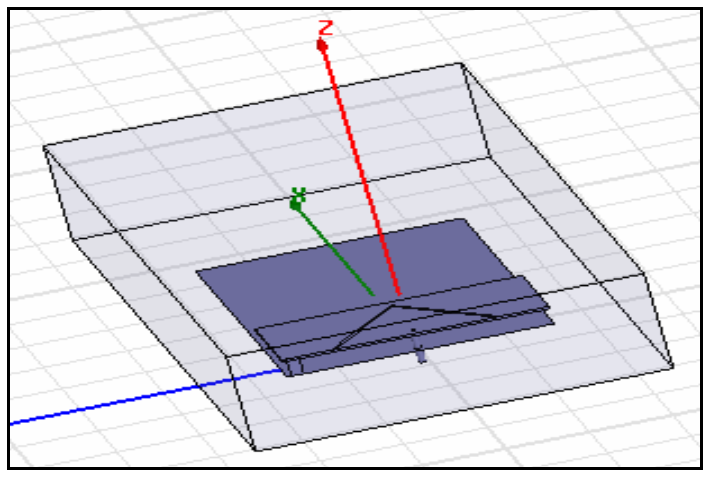

(c)

Figure 1. Different views of the designed antenna; (a) front view; (b) side view; (c) perspective view.

To compute the resonant frequency, we have the following values: $L_{p}=31 \mathrm{~mm}, W_{p}=70 \mathrm{~mm}, W_{s \max }=3 \mathrm{~mm}$. The theoretical Fris $790 \mathrm{MHz}$. The obtained frequency is then not far from $824 \mathrm{MHz}$ the first frequency of GSM850 band. In fact, there is no equation (not empirical) to determine the resonant frequency for a PIFA that contains not only the patch dimensions but also the other parameters that can affect the antenna characteristics. For this, the author will make constant the patch dimensions that are the mean parameters can furnish the resonant frequency and he will vary (following the scenario 3) firstly the height, secondly and simultanously the length $L_{g}$, the width $W_{s}$, the distance $D$. Finally, the author will vary the feeding point position $p$ and at last and simultanously undependably the other parameters (ground plan dimensions $L_{g}$, height of radiating plate $h$, feeding point position $p$, shorting plate Width $W_{s}$ and position $D$ ). 


\subsection{The Choice of the Height $h$}

The height $h$ is the distance between the top plate and the ground plane. In order to eliminate the effects of the ground plane, the patched is placed on the edge of an infinite ground plane (in HFSS, the choice of the infinite ground plan can be made during the definition of boundaries) at a height varying from $6 \mathrm{~mm}$ to $13 \mathrm{~mm}$.

From the simulation result shown by Figure 2, the optimal height $h$ is for $h=11 \mathrm{~mm}$ because it gives values $S_{11}$ most important and closer to central frequencies of both bands ( $859 \mathrm{MHz}$ and $1920 \mathrm{MHz}$ ). This height is a compliant (it will be nearly the handset thickness).

\subsection{Thesimultaneous Choice of the Ground Plan Length $L_{g}$, the Short Plate Position $D$ and the Width $W_{s}$}

The height $h$ is taken then equal to $11 \mathrm{~mm}$. It's an adequate height because the PIFA will be mounted on a GSM handset (the height is practically close to handset thickness). We will vary simultaneously the ground plane

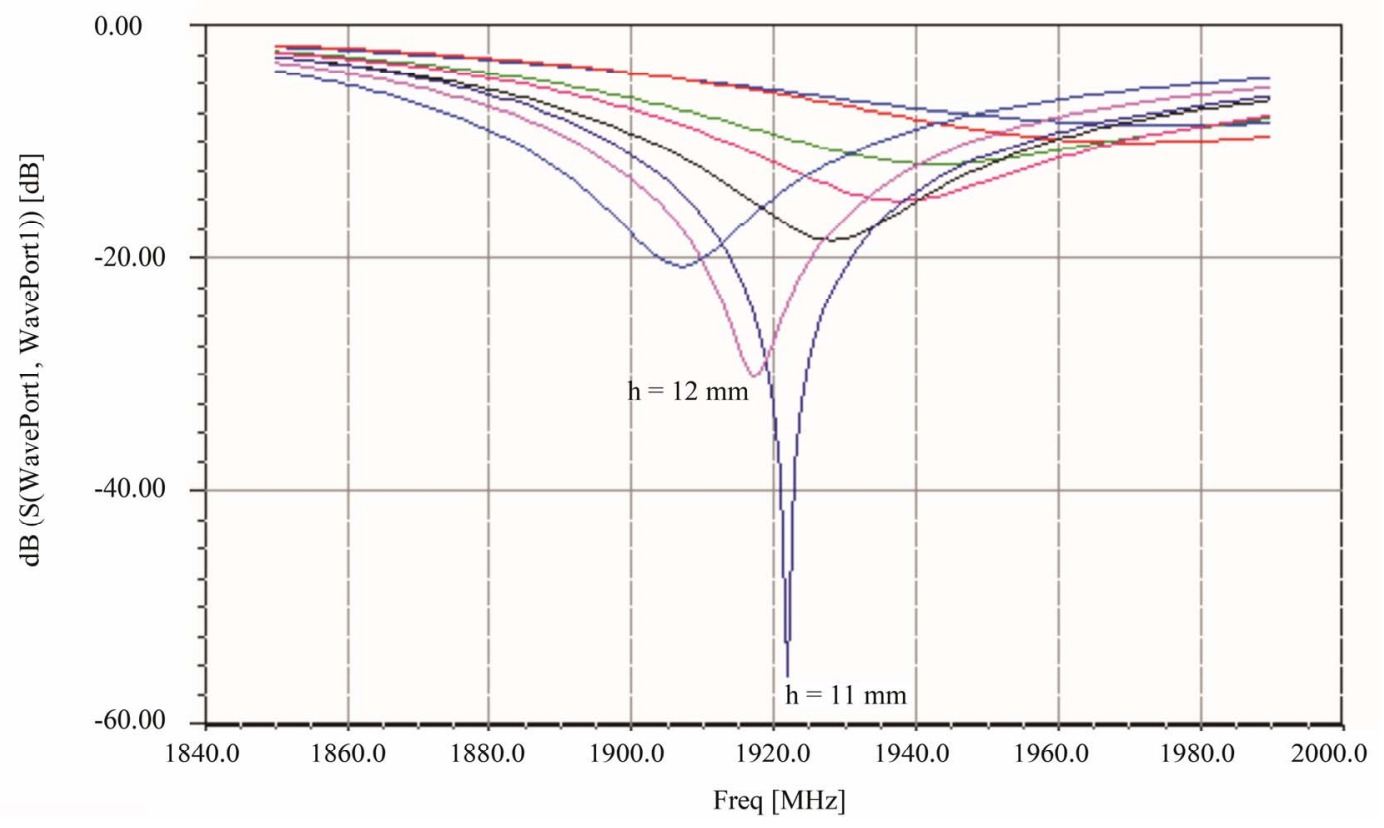

(a)

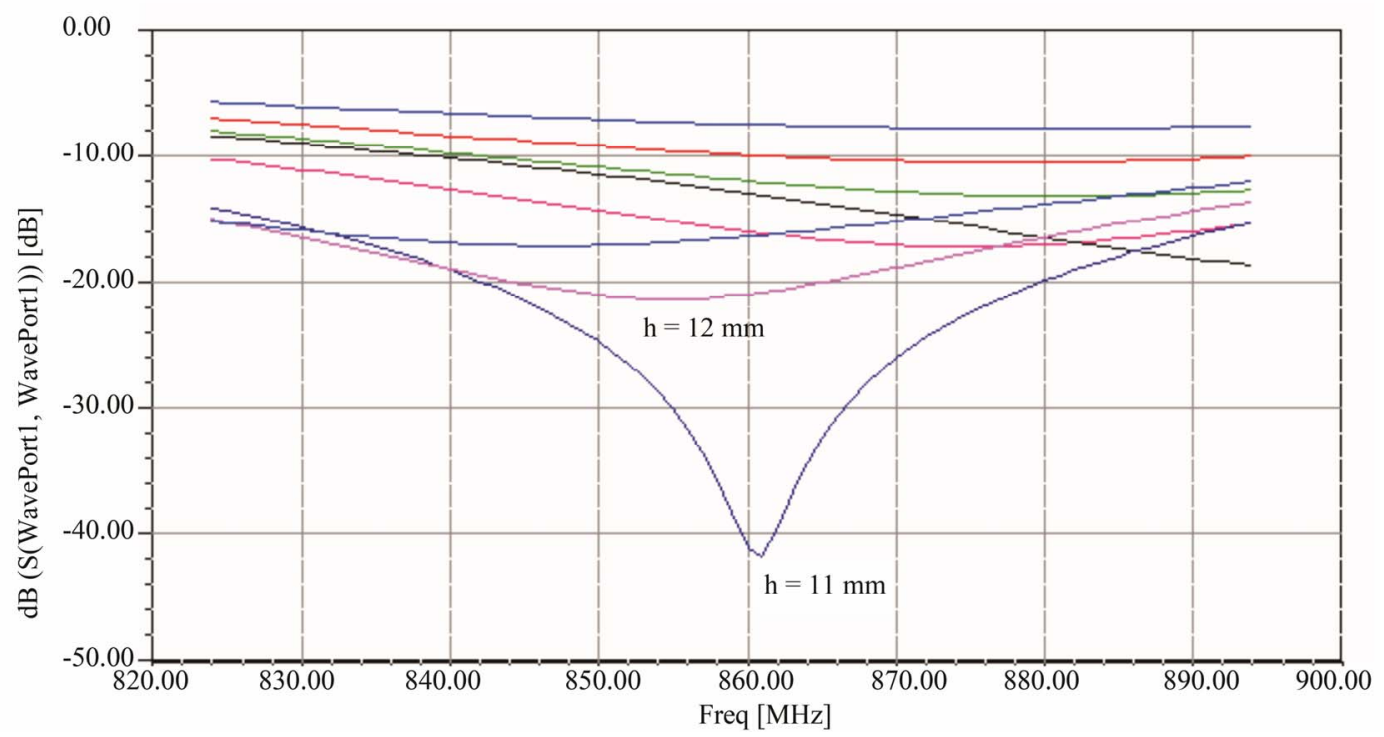

(b)

Figure 2. $h$-parametric simulation results for GSM850 and PCS bands. (a) for GSM850; (b) for PCS1900. 

Based on Parametric Simulations

length $L_{g}$ from $80 \mathrm{~mm}$ to $140 \mathrm{~mm}$, D will vary from 29 $\mathrm{mm}$ to $34 \mathrm{~mm}$ and the width $W_{s}$ from $1 \mathrm{~mm}$ to $3 \mathrm{~mm}$. We will then choose our antenna configuration from $7 \times 6 \times$ $3=126$ possibilities. The Figures 3(a) shows the results

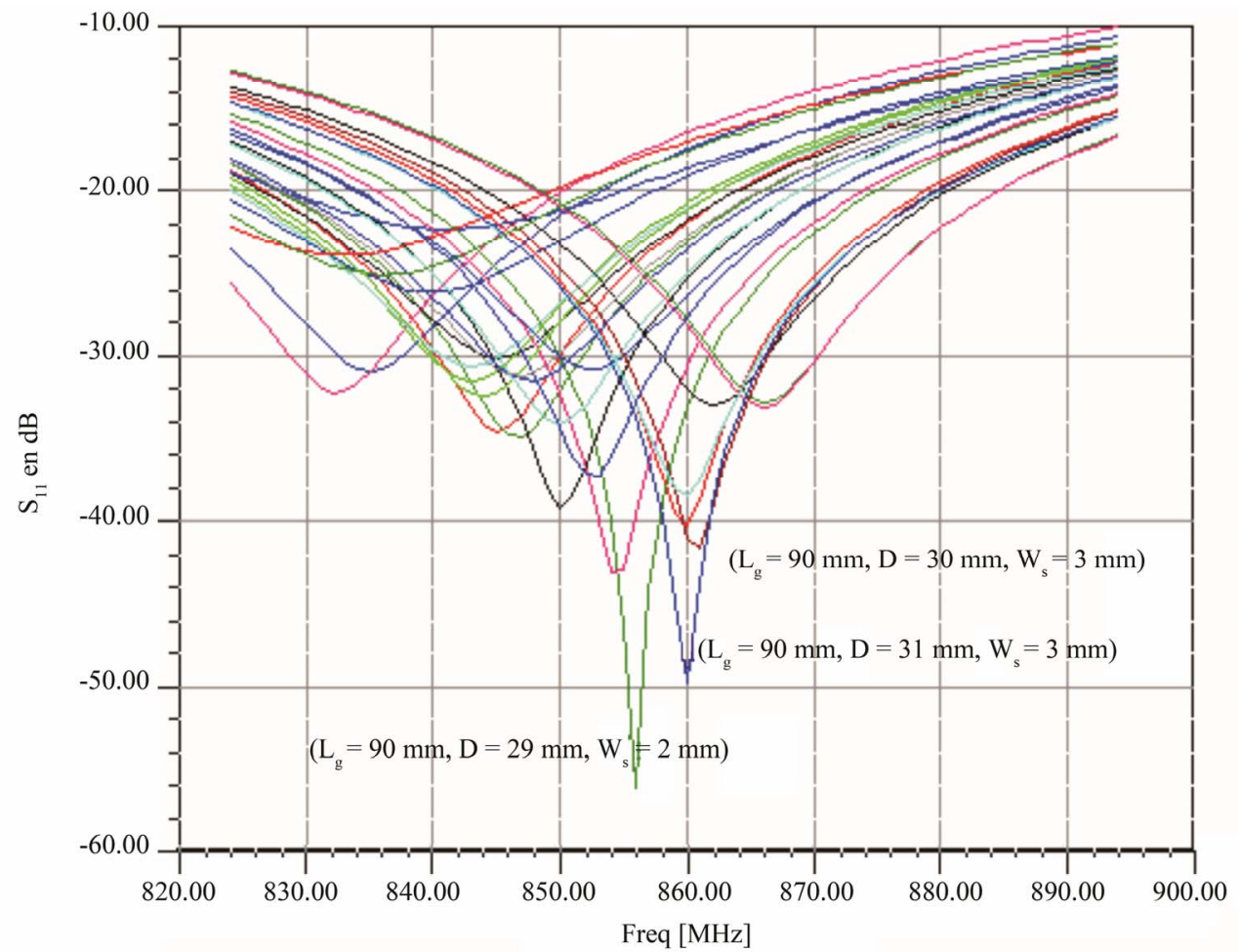

(a)

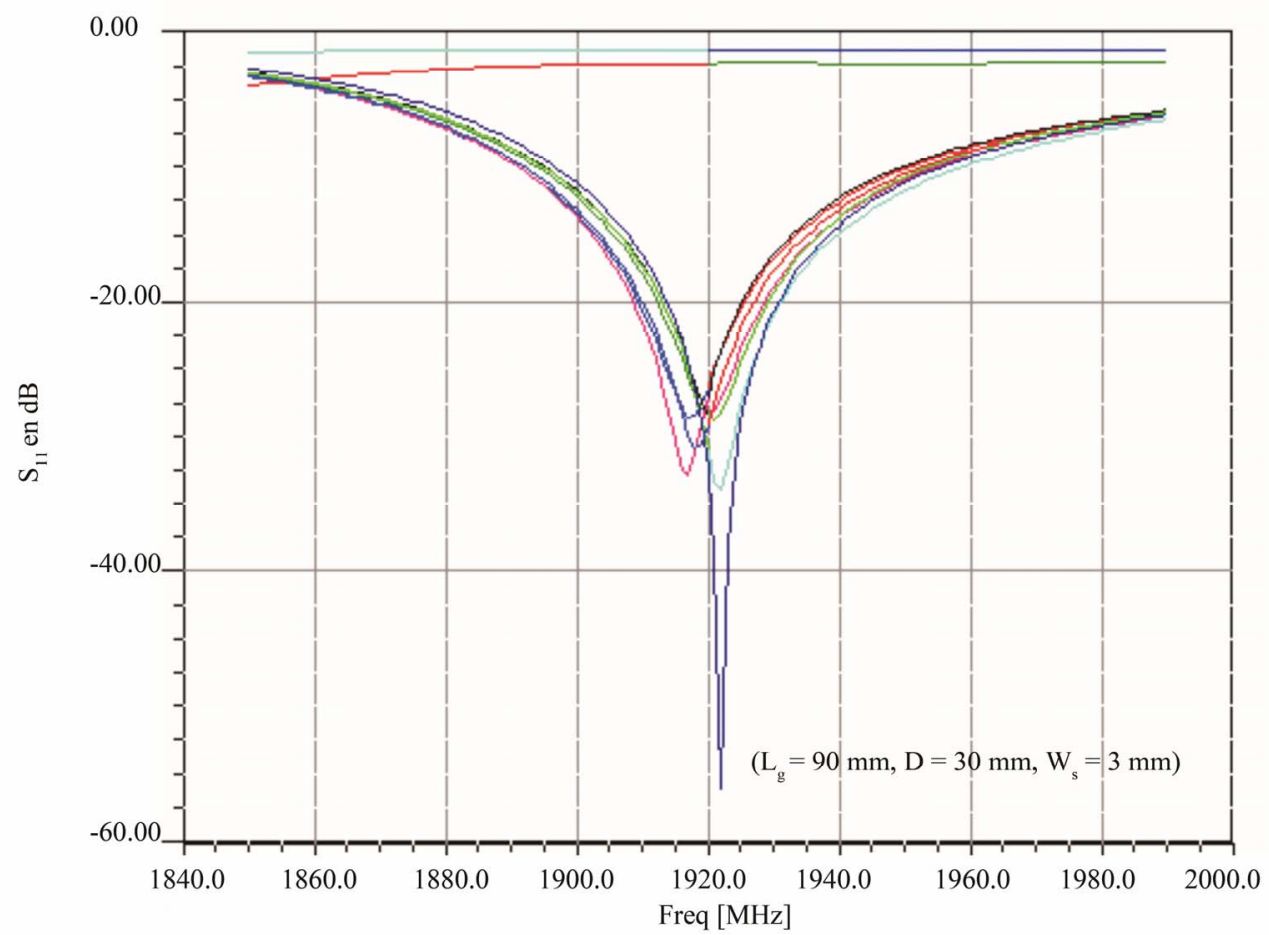

(b)

Figure 3. Tri-parametric simulation results; (a) for GSM850 band; (b) for PCS1900 band. 
tion $\left(L_{g}=90 \mathrm{~mm}, D=30 \mathrm{~mm}, W_{s}=3 \mathrm{~mm}\right)$ that is one of the three configurations related in Figure 3. We can of the tri-parametric simulation for GSM 850 band. From Figure 3, there are three curves that present minimal $S_{11}$ values and close to the central frequency $859 \mathrm{MHz}$. The three configurations are as indicated in Figure 3(a) $\left(L_{g}=\right.$ $\left.90 \mathrm{~mm}, D=31 \mathrm{~mm}, W_{s}=3 \mathrm{~mm}\right),\left(L_{g}=90 \mathrm{~mm}, D=30\right.$ $\left.\mathrm{mm}, W_{s}=3 \mathrm{~mm}\right)$ and $\left(L_{g}=90 \mathrm{~mm}, D=29 \mathrm{~mm}, W_{s}=2\right.$ $\mathrm{mm})$. We Will now check the simulation result for the three configurations but for PCS band. The result is shown in Figure 3(b).

The Figure 3(b) shows a $S_{11}$ peak for the configuraconsider the triplet ( $L_{g}=90 \mathrm{~mm}, D=30 \mathrm{~mm}, W_{s}=3 \mathrm{~mm}$ ) a very interesting trade-off configuration for both bands.

\subsection{The Choice of the Feeding Point Position $p$}

We have then chosen the parameters $h, L_{g}, D$ and $W_{s}$. We can now look for the effect of the feeding point position $p$ to enhance the bandwidth or the input impedance. It is calculated from the rear edge of the patch. We will vary the $p$ parameter from $2 \mathrm{~mm}$ to $16 \mathrm{~mm}$ (the centre). The value $p=1$ can't be taken because the feeding point is theoretically a circle that has a radius. The result is shown on Figure 4. We can consider the peak for $p=3$ $\mathrm{mm}$ an interesting position for feeding for PCS band. We will see for GSM band as shown in Figure 5. It is an adequate position because it gives a $S_{11}$ peak very closely to the central frequency of the GSM850 band.

\subsection{The Third Scenario Results}

The results of parametric simulations are exposed in the following. We can see in Figure 6 two peaks of $S_{11}$ parameter, one is around $860 \mathrm{MHz}$ (very close to the GSM850 central frequency $859 \mathrm{MHz}$ ), the second peak is around $1922 \mathrm{MHz}$ (very close to the PCS central frequency $1920 \mathrm{MHz}$ ). Also, the $S_{11}$ values out of both bands are near 0 , that means the designed antenna can't interfere with other radiations. We can also run the simulation by refining the sweep interval for more precision. As given exactly by simulations tables, we note $S_{11}$ $=-14.04 \mathrm{~dB}$ for $824 \mathrm{MHz}$ (the low frequency of the GSM850 band), $S_{11}=-14.89 \mathrm{~dB}$ for $894 \mathrm{MHz}$ (the high frequency of the GSM band), $S_{11}=-2.7 \mathrm{~dB}$ for 1850 $\mathrm{MHz}$ (the low frequency of the PCS band), $S_{11}=-6.09$ $\mathrm{dB}$ for $1990 \mathrm{MHz}$ (the high frequency of the PCS band).

\subsubsection{The Bandwidth and VSWR}

We obtain as shown in Figure 7(a) for GSM850 band a VSWR $=1.49$ for $824 \mathrm{MHz}$ (the lowest frequency), VSWR $\min =1.03$ for $860 \mathrm{MHz}$ (the resonant frequency), VSWR $=1.43$ for $894 \mathrm{MHz}$ (the highest frequency). The VSWR is at its minimum, it's very interesting result. Also, The GSM bandwidth $(70 \mathrm{MHz})$ is for the designed antenna a 1:1.5 VSWR bandwidth and the antenna presents a presents a $1: 2$ bandwidth equal to 120 $\mathrm{MHz}$. It is considered a very interesting result.

Also, we obtain as shown in Figure 7(b) for PCS band

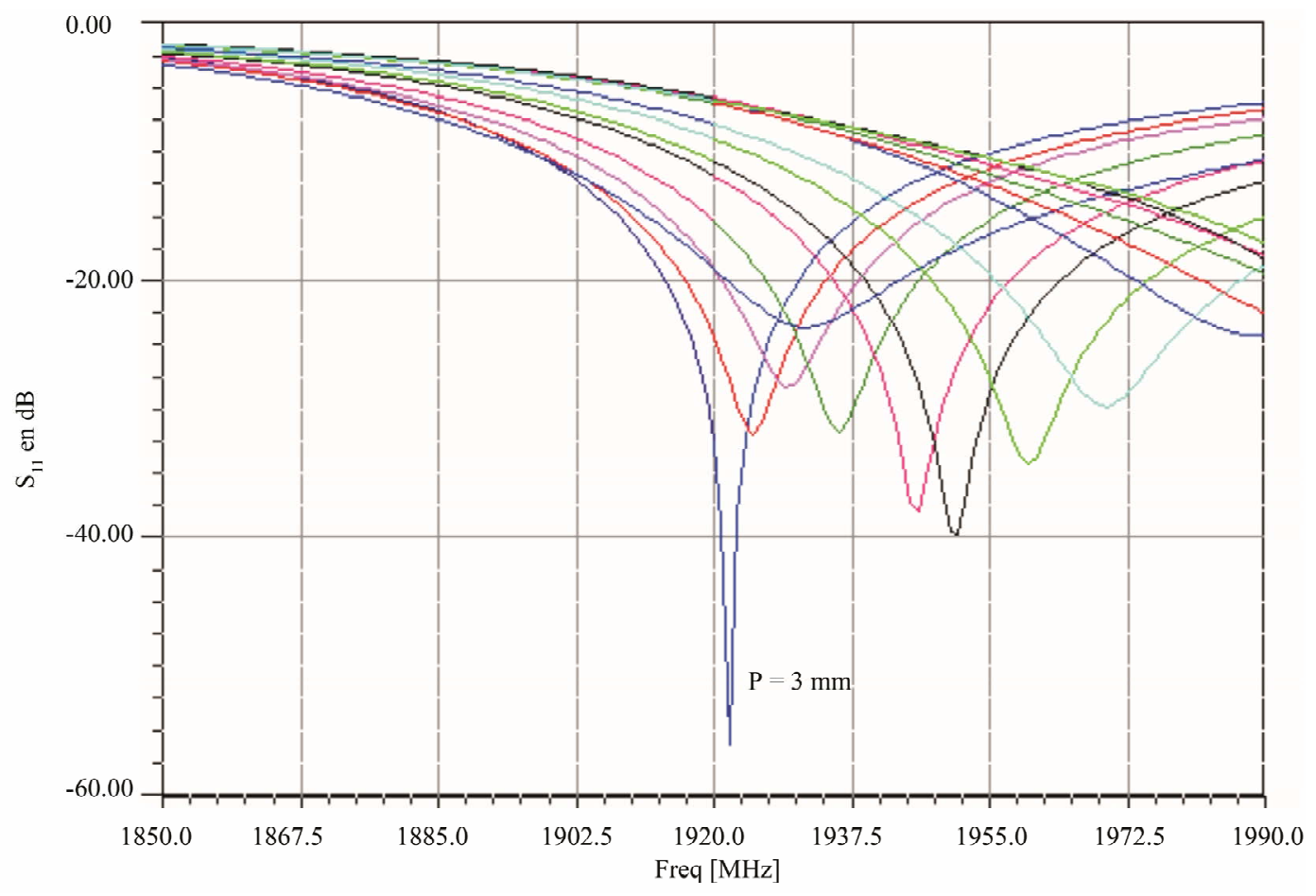

Figure 4. Feeding point position parametric simulation results for PCS1900 band. 


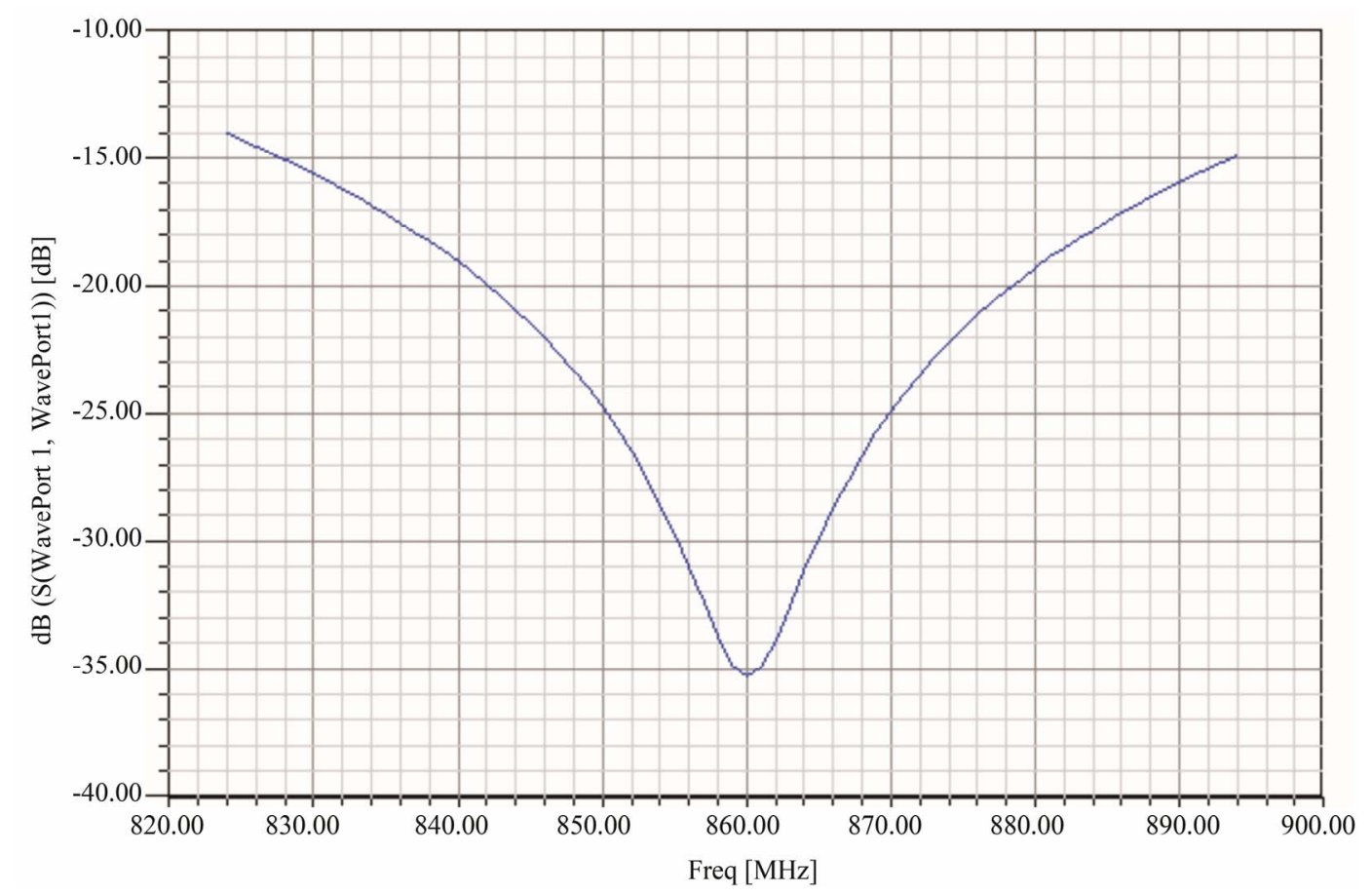

Figure 5. The selected configuration in GSM850 band.

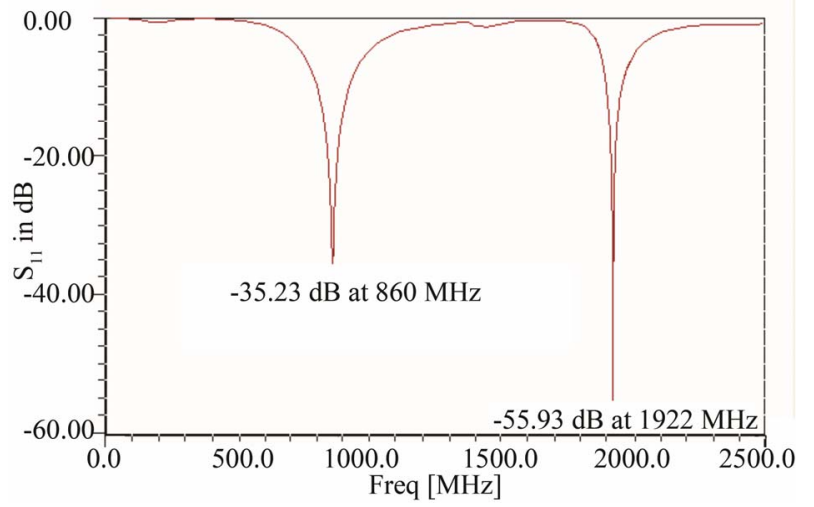

Figure 6. $S_{11}$ depending on frequency for $(0-2400 \mathrm{MHz})$.

a VSWR $=6.47$ for $1850 \mathrm{MHz}$ (the lowest frequency), VSWR $\min =1.00$ for $1922 \mathrm{MHz}$ (the resonant frequency), $\mathrm{VSWR}=1.00$ for $1990 \mathrm{MHz}$ (the highest frequency). The VSWR is at its minimum, it's a very interesting result. Also, The PCS bandwidth (140 MHz) is for the designed antenna a 1:6.47 VSWR bandwidth and the antenna presents a 1:2 bandwidth equal to $63 \mathrm{MHz}$.

\subsubsection{The Impedance in the Feeding Point}

The Figure 8 shows a regular impedance smith chart with interesting parameters of reflection, impedance, VSWR and Q. We can see very close values between the impedances (input and port). The feeding point position is then confirmed that is very adequate because it presents a very interesting adaptation.

\subsubsection{The Antenna Parameters}

The simulations results are summarized in Table 1. The obtained gain $\mathrm{G}$ is $1 \mathrm{dBi}$ and the radiation efficiency is 1.0085 .

\subsubsection{The Diagram Pattern}

We can confirm by the Figure 9 that (xz) is the E-plane. Also, by the tables the E-field has its maximum in (phi = $0 \mathrm{deg}$ and theta $=-36 \mathrm{deg})$.

\section{Comparison between the Three Scenarios}

The mean results are shown by Table 2 . We can detect that the second scenario gives more intersting results, the simultanous parametric simulations increas the probability to find an optimized configuration.

\section{The Selected Methodology}

By the precedent comparision, the author concluded about the following methodology that is improvement of the second scenario. To design antenna, we must group by the parameters that have the same order of magnitude to make simultanous parametric simulation and also varying successively the parameters wich have different order of magnitude. For this, the following methodology is efficient to design optimized mulibandes PIFAs:

- Choose the patch dimensions and shape by applying the theoretical formula of resonnant frequency.

- Vary $h$ from some millimeters to the maximun ac- 


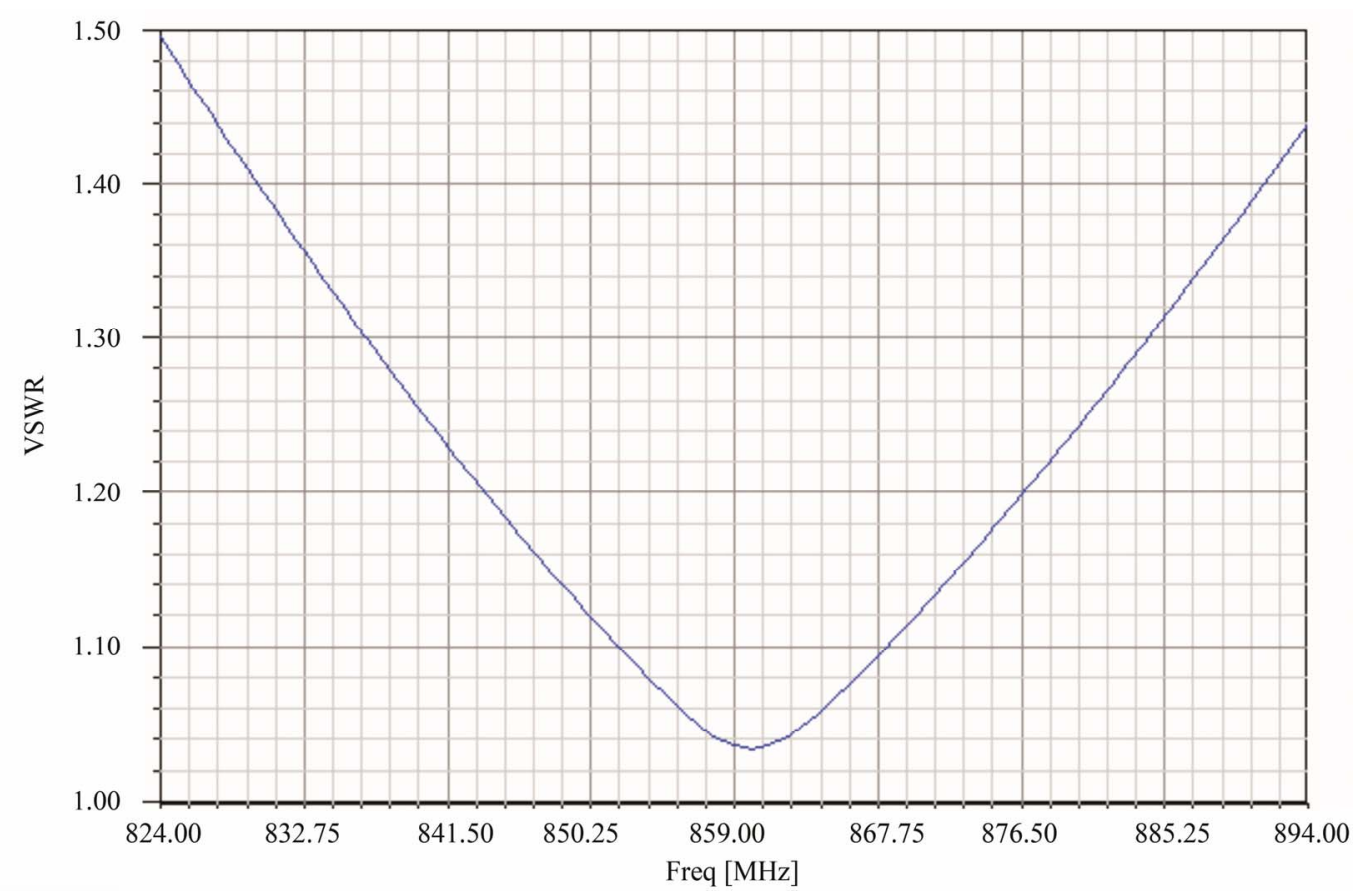

(a)

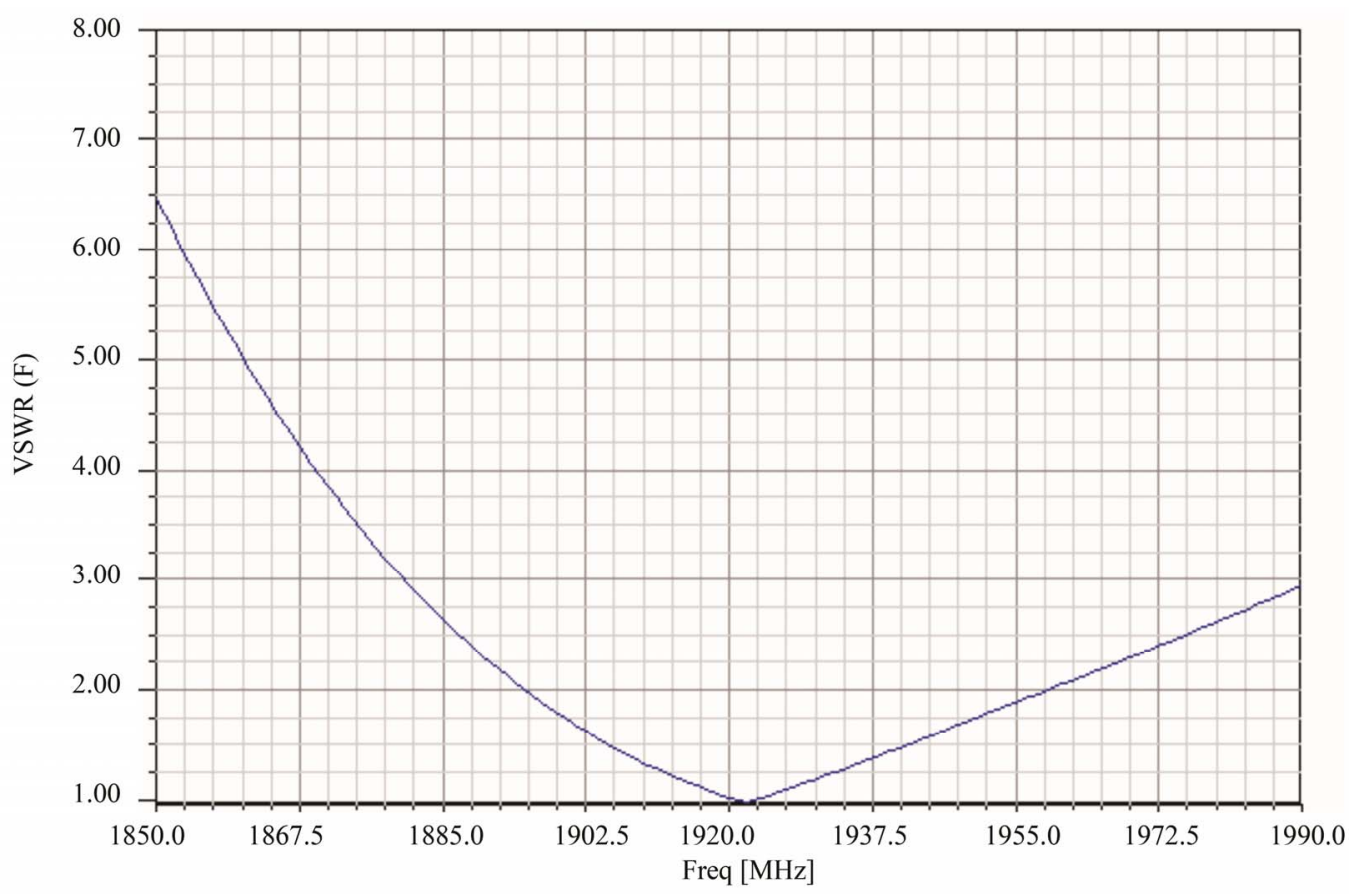

(b)

Figure 7. The VSWR depending on the frequency for both bands.

cepted thickness of the handset (in the hypothesis of an infinite ground plan that can be chosen in the simulation by HFSS). The height $\mathrm{h}$ is then selected. for multiband antenna, the optimal value should be a trade-off for different bands.

- Vary the ground plan dimensions regarding the maxi- mum dimensions of the PCB card where the antenna will be mounted. The ground plan dimensions are then chosen.

- Make a simultanous parametric simulations for the parameters concerning the feeding point and the shorting plate (as $W_{s}, D, p$ ). This step is compliant for 


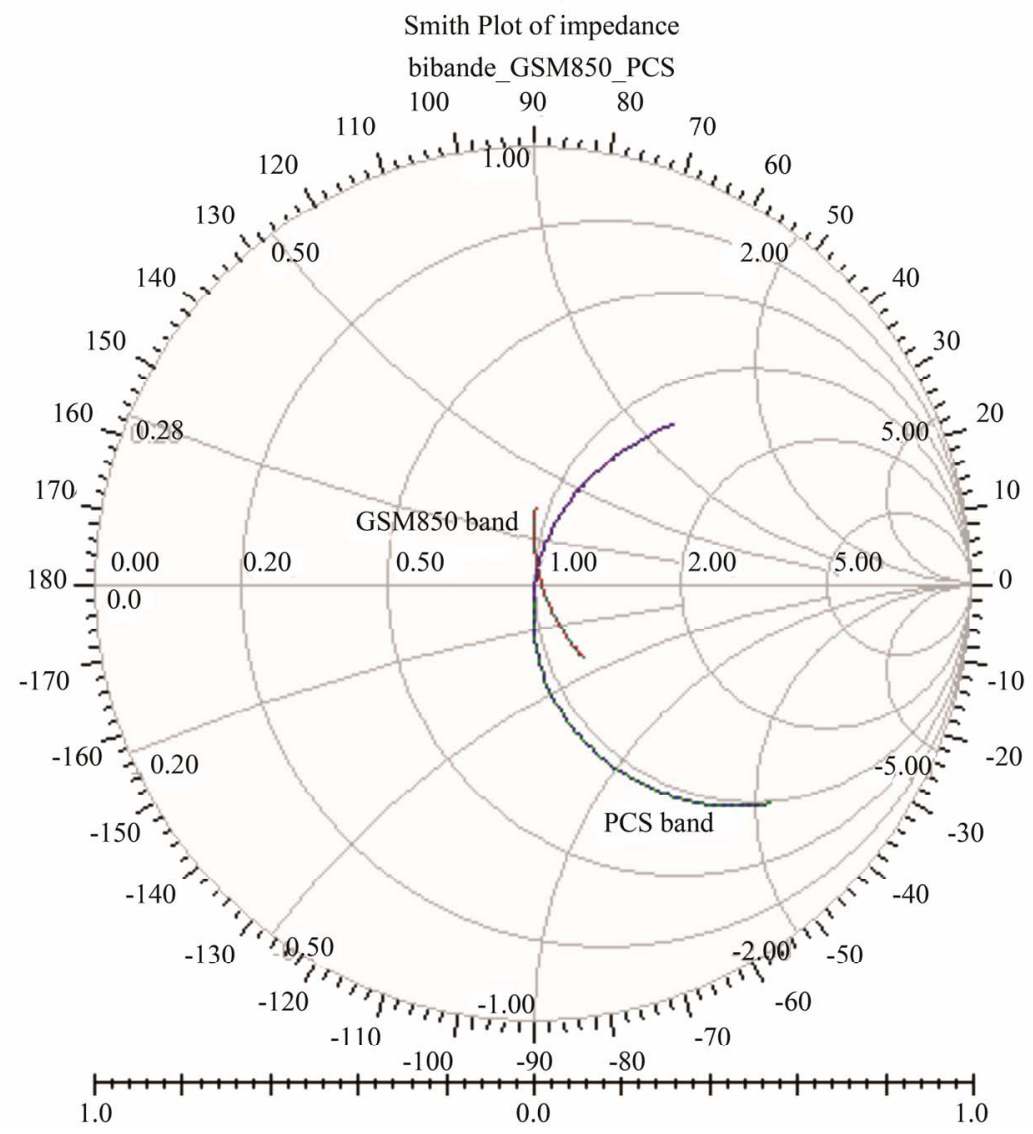

Figure 8. The impedance smith chart for both bands.

Table 1. The design antenna parameters and dimensions.

\begin{tabular}{|c|c|}
\hline Antenna parameter & $\begin{array}{l}\text { Value of the parameter } \\
\text { GSM850 PCS1900 }\end{array}$ \\
\hline Patch Length $L_{p}$ & $31 \mathrm{~mm}$ \\
\hline Patch width $W_{p}$ & $70 \mathrm{~mm}$ \\
\hline Ground plan length $L_{g}$ & $90 \mathrm{~mm}$ \\
\hline Ground plan width $W_{g}$ & $70 \mathrm{~mm}$ \\
\hline Height $\mathrm{h}$ & $11 \mathrm{~mm}$ \\
\hline Short plate width $W_{s}$ & $3 \mathrm{~mm}$ \\
\hline Short plate position $D$ & $30 \mathrm{~mm}$ \\
\hline Feeding point position & $3 \mathrm{~mm}$ \\
\hline Resonnat frequency & $860 \mathrm{MHz}, 1922 \mathrm{MHz}$ \\
\hline Peak $S_{11}$ & $-36 \mathrm{~dB},-56 \mathrm{~dB}$ \\
\hline 1:2 VSWR bandwith & $63 \mathrm{MHz}, 40 \mathrm{MHz}$ \\
\hline Peak Gain & $1 \mathrm{~dB}$ \\
\hline Peak directivity & $1 \mathrm{~dB}$ \\
\hline Radiation efficiency & $85 \%$ \\
\hline E total max & Phi $=0$ deg, Theta $=-36 \mathrm{deg}$ \\
\hline
\end{tabular}

Table 2. Comparision of the three scenarios.

\begin{tabular}{|c|c|c|c|c|c|}
\hline \multirow[b]{2}{*}{$\begin{array}{l}\text { Antenna } \\
\text { parameter }\end{array}$} & \multirow{2}{*}{$\begin{array}{l}\text { Scenario } 1 \\
\text { Single Band }\end{array}$} & \multicolumn{2}{|c|}{ Scenario 2} & \multicolumn{2}{|c|}{ Scenario3 } \\
\hline & & $\begin{array}{l}\text { First } \\
\text { band }\end{array}$ & $\begin{array}{l}\text { Second } \\
\text { band }\end{array}$ & $\begin{array}{l}\text { First } \\
\text { band }\end{array}$ & $\begin{array}{l}\text { Second } \\
\text { band }\end{array}$ \\
\hline $\begin{array}{l}\text { Required } \\
\text { bandwith }\end{array}$ & 140 & \multicolumn{2}{|c|}{70,170} & \multicolumn{2}{|c|}{70,140} \\
\hline $\begin{array}{c}-10 \mathrm{db} \\
\text { bandwith }\end{array}$ & $>140 \mathrm{MHz}$ & \multicolumn{2}{|c|}{$\begin{array}{c}>70 \mathrm{MHz}, 65 \\
\mathrm{MHz}\end{array}$} & \multicolumn{2}{|c|}{$\begin{array}{c}>70 \mathrm{MHz} \\
40 \mathrm{MHz}\end{array}$} \\
\hline $\begin{array}{l}\text { 1:1.5 VSWR } \\
\text { bandwith }\end{array}$ & $130 \mathrm{MHz}(93 \%)$ & \multicolumn{2}{|c|}{$\begin{array}{c}>90 \mathrm{MHz} \\
(>130 \%) \\
40 \mathrm{MHz}\end{array}$} & \multicolumn{2}{|c|}{$70(100 \%), 35 \mathrm{MHz}$} \\
\hline Peak $S_{11}$ & $-65 \mathrm{~dB}$ & \multicolumn{2}{|c|}{$-55 \mathrm{~dB},-23 \mathrm{~dB}$} & \multicolumn{2}{|c|}{$-36 \mathrm{~dB},-56 \mathrm{~dB}$} \\
\hline Peak gain & $1.16 \mathrm{~dB}$ & \multicolumn{2}{|c|}{$12.9 \mathrm{~dB}$} & \multicolumn{2}{|c|}{$1 \mathrm{~dB}$} \\
\hline $\begin{array}{c}\text { Peak } \\
\text { directivity }\end{array}$ & $1.15 \mathrm{~dB}$ & \multicolumn{2}{|c|}{$15.2 \mathrm{~dB}$} & \multicolumn{2}{|c|}{$1 \mathrm{~dB}$} \\
\hline $\begin{array}{l}\text { Radiation } \\
\text { efficiency }\end{array}$ & 1.0085 & \multicolumn{2}{|c|}{0.84} & \multicolumn{2}{|c|}{$1 \mathrm{~dB}$} \\
\hline $\begin{array}{l}\text { Required } \\
\text { resonnant } \\
\text { frequency }\end{array}$ & $1920 \mathrm{MHz}$ & \multicolumn{2}{|c|}{$\begin{array}{l}925 \mathrm{MHz} \\
1795 \mathrm{MHz}\end{array}$} & \multicolumn{2}{|c|}{$\begin{array}{l}859 \mathrm{MHz}, \\
1920 \mathrm{MHz}\end{array}$} \\
\hline $\begin{array}{l}\text { Resonnant } \\
\text { frequency }\end{array}$ & $1924 \mathrm{MHz}$ & \multicolumn{2}{|c|}{$\begin{array}{l}926 \mathrm{MHz} \\
1804 \mathrm{MHz}\end{array}$} & \multicolumn{2}{|c|}{$\begin{array}{l}860 \mathrm{MHz}, \\
1922 \mathrm{MHz}\end{array}$} \\
\hline
\end{tabular}




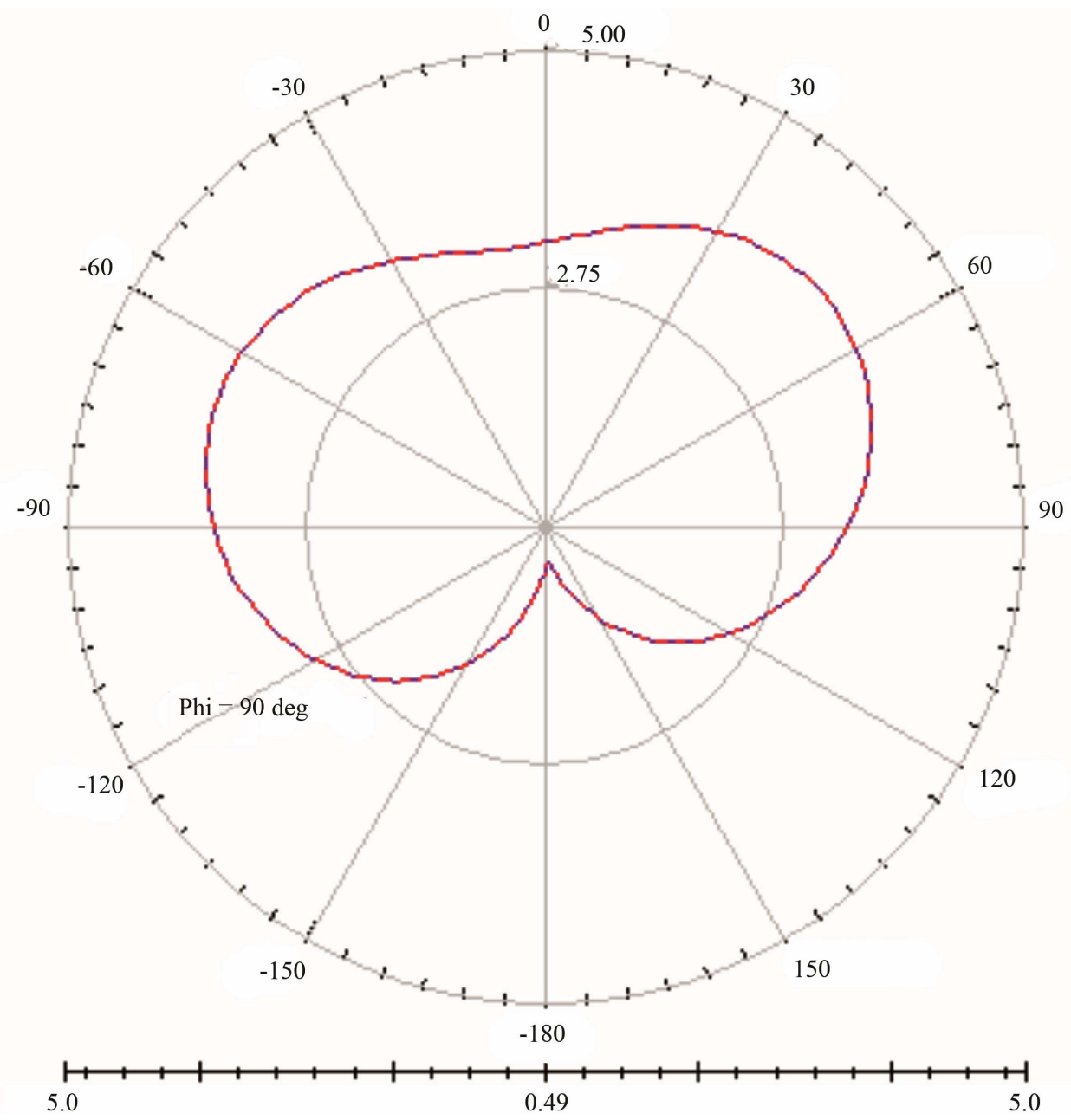

(a)
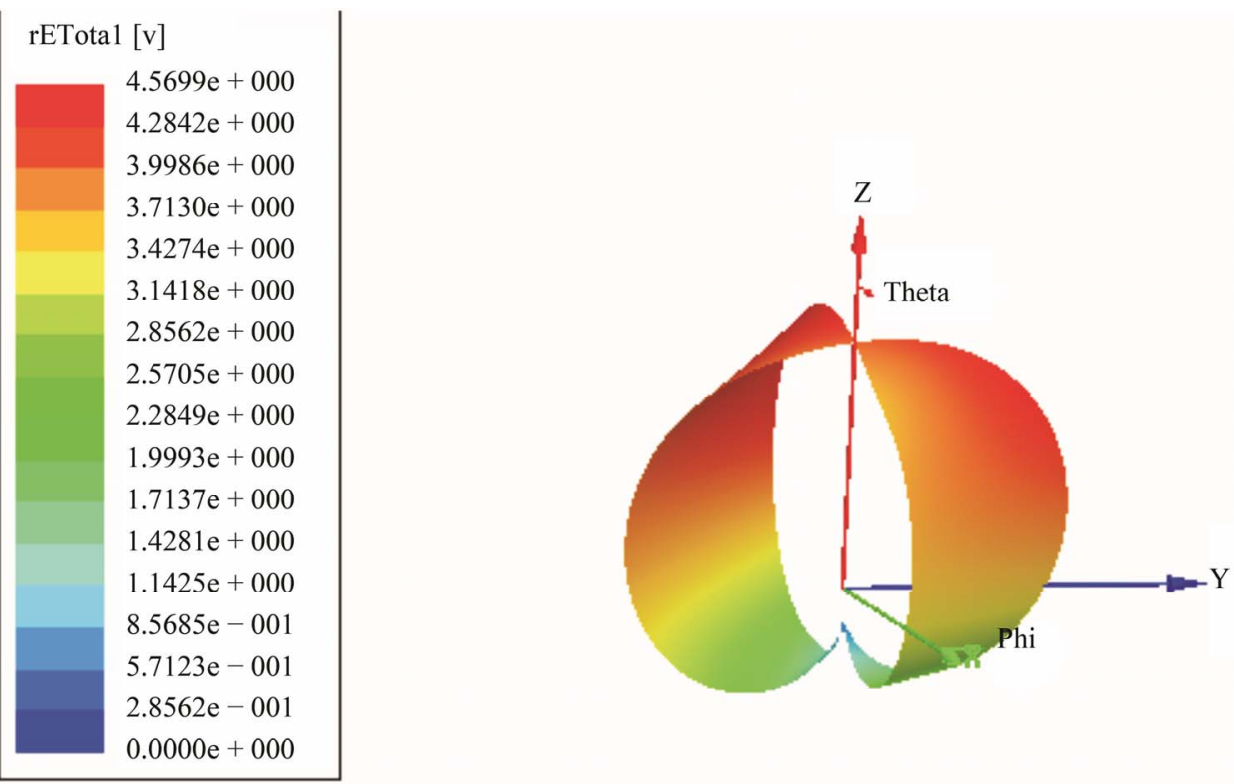

(b)

Figure 9. The E-field polar diagram pattern; (a) in 2D; (b) in 3D. 
both antenna feeding ways (probe or plate). Make a trade off choice of the optimal configuration for different bands.

- This methodology is interesting not only to design PIFA with regular shape (as studied here), but also PIFAs with bent and meandered shapes by modifing an initial regular PIFA.

\section{Conclusions}

To design a dual band (or multibands) PIFA, the author exposed a methodolgy based on parametric simulations. The parameters variations are simulated successively or simultanously by group that have the same order of magnitude. The methodogy is a formalism of precedent published works of the author concerning the parametric simulations to design PIFAs. The results are interesting and the methodogy can be used lonely or can be also combined with other design algorithms of PIFA literature.

Also, the methodology is a trade-off between differents band of the antenna because enhancement in a band affects negatively the other bands. The methodology has as goal to search an effective solution that respects the requirements and not necessary the optimal one. In comparison with precedent designed PIFAs [4,5] for different frequency bands, the methodology allows the design of antennas presenting a very high gain and directivity and also an interesting radiation efficiency for different band. The use of methodology in designing antenna is so interesting to optimize the antenna characteristics and performance. This research field is in progress and the antenna design methodology can be combined with algorithms as genetic algorithms to make more optimized antennas.

\section{REFERENCES}

[1] A. Elouadih, A. Oulad-Said and M. M. Hassani, "Design and Parametric Simulation of a Miniaturized PIFA Antenna for the PCS Band," Wireless Engineering and Technology,Vol. 4, 2013, pp. 105-111.

[2] A. Elouadih, A. Oulad-Said and M. M. Hassani, "Design and Parametric Simulation of a biband Miniaturized PIFA Antenna for the GSM900 and DCS1800 Bands," Journal of Electromagnetic Analysis and Applications, Vol. 5, No. 5, 2013, pp. 189-195. doi:10.4236/jemaa.2013.55030

[3] K. L. Virga and Y. Rahmat-Samii, "Low-Profile Enhanced Bandwith PIFA for Wireless Communications Packaging," IEEE Transactions on Microwave Theory and Techniques, Vol. 45, No. 10, 1997, pp. 1879-1888. doi:10.1109/22.641786

[4] W.-J. Liao, T.-M Liu and S.-Y. Ho, "Miniaturized PIFA Antenna for $2.4 \mathrm{GHz}$ ISM Band Applications," IEEE proceedings of the 6th European Conference on Antennas and Propagation (EUCAP), Prague, March 2012, pp. 3034-3037.

[5] A. K. Skrivervik, J.-F. Zürcher, O.Staub and J. R. Mosig, "PCS Antenna Design: The Challenge of Miniaturization," IEEE Antennas and Propagation Magazine, Vol. 43, No. 4, 2001, pp. 12-27. doi:10.1109/74.951556

[6] R. Rahul Raut Dessai and H. G. Virani "Proposed Algorithm and Parametric Study of PIFA for WiFi Band," IJERA Journal, Vol. 3, No. 3, 2013, pp. 680-685.

[7] H. T. Chattha, Y.-Huang, X. Zhu and Y. Lu, "An Empirical Equation for Predicting the Resonant Frequency of PIFAs," AWPL IEEE, Vol. 8, 2009, pp. 856-860.

[8] H. T. Chattha, Y.-Huang, M. K. Ishfaq and S. J. Boyes, "A Comprehensive Parametric Study of Planar Inverted-F Antenna," Wireless Engineering and Technology, Vol. 3, 2012, pp. 1-11. doi:10.4236/wet.2012.31001

[9] "PIFA: The Planer Inverted-F Antenna." www.antenna-theory.com/antennas/patches/pifa.php 